\title{
Cryptococcosis and Cryptococcus
}

\author{
Elaine Cristina Francisco (iD) - Auke W. de Jong (D) Ferry Hagen (1)
}

Received: 10 April 2021 / Accepted: 23 June 2021 / Published online: 5 July 2021

(C) The Author(s) 2021

Keywords Cryptococcus neoformans.

Cryptococcus gattii $\cdot$ Diagnostics $\cdot$ Species

complexes · Taxonomy $\cdot$ Treatment

Cryptococcosis is the collective heading of infections caused by members of the basidiomycetous yeast genus Cryptococcus, a notorious pathogen since the advent of the HIV/AIDS-pandemic. A cryptococcal infection usually manifests itself as a pneumonia and/ or meningitis. The genus includes ten species, most of them belonging to the $C$. gattii/C. neoformans species complexes, and some non-pathogenic species $(C$. amylolentus, $C$. depauparatus and C. luteus) [1]. Previous rare causes of cryptococcosis are now accommodated in other genera (e.g. Naganishia

Handling Editor: Min Chen

E. C. Francisco

Laboratório Especial de Micologia, Division of Infectious Diseases, Universidade Federal de São Paulo, São Paulo, Brazil

E. C. Francisco · A. W. de Jong · F. Hagen ( $\)$

Westerdijk Fungal Biodiversity Institute, Uppsalalaan 8, Utrecht 3584CT, The Netherlands

e-mail: f.hagen@wi.knaw.nl;

f.hagen@gmail.com

\section{A. W. de Jong · F. Hagen}

Department of Medical Microbiology, University Medical

Center Utrecht, Utrecht, The Netherlands albida, Naganishia diffluens and Papilliotrema laurentii) [1, 2].

Cryptococcus neoformans sensu stricto (previously C. neoformans variety grubii) is globally the major cause of systemic cryptococcosis among immunocompromised individuals. It is strongly associated with bird excreta, especially pigeon droppings [3]. Cryptococcus deneoformans (formerly C. neoformans variety neoformans) is less common but remain a major cause of cryptococcosis in Europe [3]. This applies to the interspecies hybrid $C$. deneoformans $\times C$. neoformans, which occurs predominantly in Mediterranean Europe [3]. Relevant difference between $C$. neoformans and $C$. deneoformans is that the latter is associated with skin-infections and more often seen in elderly patients $[3,4]$.

Cryptococcus gattii sensu lato (formerly C. neoformans variety gattii) became notorious due to the unprecedented outbreak on Vancouver Island (British Columbia, Canada). Until then, C. gattii was recognized as a pathogen exclusive to tropical and subtropical regions [5]. C. gattii is -like C. neoformans- a species complex, it comprises six lineages of which five are recognized as species while the sixth needs to be named $[3,6]$. The ' $C$. gattii VGII-outbreak lineage' is now called $C$. deuterogattii. The environmental niches are trees and plants, and it is globally distributed like its sibling $C$. gattii sensu stricto. As both species occur in the environment of temperate climate zones it is obvious that they cannot longer be 


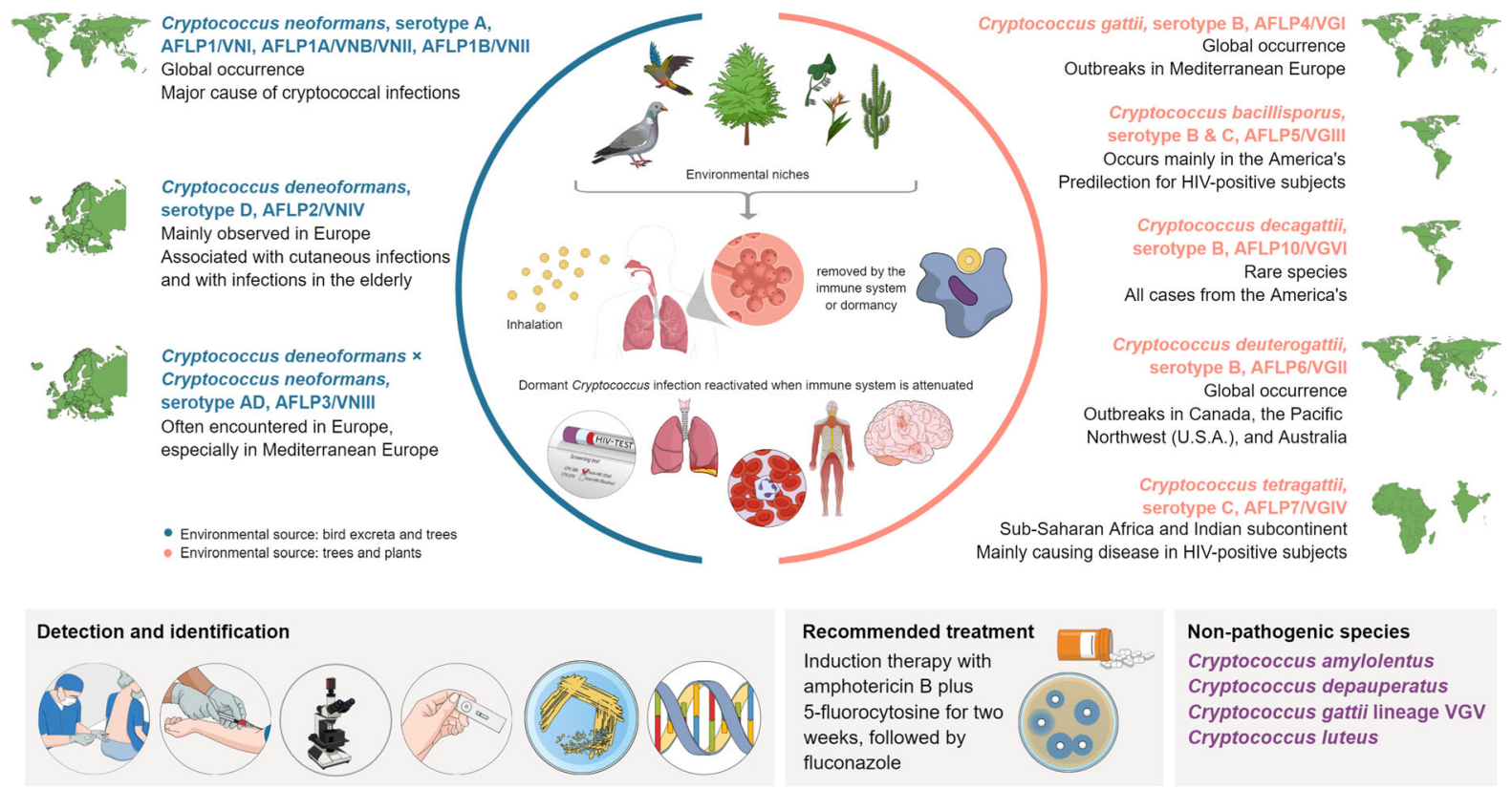

Fig. 1 Characteristics of the pathogenic members in the Cryptococcus gattii/Cryptococcus neoformans species complexes. The upper part shows the 7 recognized species with serotype, AFLP genotype/molecular type, and geographic distribution. At the left side the $C$. neoformans species complex members, at the right side the $C$. gattii species complex

regarded as strict (sub)tropical pathogens. The remaining three pathogenic species have a predilection for the immunocompromised host. C. bacillisporus and $C$. decagattii infections are mainly reported from the America's, with some inexplicable cases outside these continents [3, 5]. Cryptococcus tetragattii is, like $C$. neoformans, a frequent cause of cryptococcal meningitis among HIV-positive patients from sub-Saharan African and the Indian subcontinent (Fig. 1).

The cryptococcal polysaccharide capsule is an important virulence factor and an unmistakably aid in diagnostics. Cryptococcosis can be diagnosed by rapid and low-cost lateral flow assay, negative staining of CSF, culture, and molecular tools.

PCR-fingerprinting, AFLP genotyping, microsatellite typing, multi-locus sequencing typing and whole genome sequencing are widely used to investigate the molecular epidemiology [3, 6-9] (Fig. 1). The bipolar mating system, a set of genes with interacting MATa and MAT $\alpha$ alleles, as well as mutation accumulation during clonal expansion, drives genetic diversity. From an epidemiological point-of-view members. Central to this are theenvironmental source and route of infection. The lower part depicts detection and identification methods, recommended treatment (based on [10]), and an overview of non-pathogenic species in the genus Cryptococcus (based on $[1,2,6]$ )

(molecular) species-level identification is of importance and could contribute to adequate treatment.

Recommended treatment is a 2-weeks induction therapy with amphotericin B plus 5-fluorocytosine, followed by fluconazole as suppressive therapy [10]. C. gattii sensu lato infections need to be more aggressively treated than $C$. neoformans sensu lato, as the former produce cryptococcoma's that are difficult to eradicate [10]. Antifungal susceptibility differences have been reported between species and it can be expected that in the future treatment is speciesfocussed rather than on the species complex [3].

Open Access This article is licensed under a Creative Commons Attribution 4.0 International License, which permits use, sharing, adaptation, distribution and reproduction in any medium or format, as long as you give appropriate credit to the original author(s) and the source, provide a link to the Creative Commons licence, and indicate if changes were made. The images or other third party material in this article are included in the article's Creative Commons licence, unless indicated otherwise in a credit line to the material. If material is not included in the article's Creative Commons licence and your intended use is not permitted by statutory regulation or exceeds the permitted use, you will need to obtain permission directly 
from the copyright holder. To view a copy of this licence, visit http://creativecommons.org/licenses/by/4.0/.

\section{References}

1. Liu XZ, Wang QM, Göker M, Groenewald M, Kachalkin AV, Lumbsch HT, Millanes AM, Wedin M, Yurkov AM, Boekhout T, Bai FY. Towards an integrated phylogenetic classification of the Tremellomycetes. Stud Mycol. 2015;81:85-147. https://doi.org/10.1016/j.simyco.2015.12. 001.

2. Khawcharoenporn T, Apisarnthanarak A, Mundy LM. Nonneoformans cryptococcal infections: a systematic review. Infection. 2007;35(2):51-8. https://doi.org/10.1007/ s15010-007-6142-8.

3. Hagen F, Khayhan K, Theelen B, Kolecka A, Polacheck I, Sionov E, Falk R, Parnmen S, Lumbsch HT, Boekhout T. Recognition of seven species in the Cryptococcus gattiil Cryptococcus neoformans species complex. Fungal Genet Biol. 2015;78:16-48. https://doi.org/10.1016/j.fgb.2015.02. 009.

4. Dromer F, Mathoulin S, Dupont B, Letenneur L, Ronin O. Individual and environmental factors associated with infection due to Cryptococcus neoformans serotype D French Cryptococcosis Study Group. Clin Infect Dis. 1996;23(1):91-6. https://doi.org/10.1093/clinids/23.1.91.

5. Springer DJ, Chaturvedi V. Projecting global occurrence of Cryptococcus gattii. Emerg Infect Dis. 2010;16(1):14-20. https://doi.org/10.3201/eid1601.090369.

6. Farrer RA, Chang M, Davis MJ, van Dorp L, Yang DH, Shea T, Sewell TR, Meyer W, Balloux F, Edwards HM, Chanda D, Kwenda G, Vanhove M, Chang YC, Cuomo CA,
Fisher MC, Kwon-Chung KJ. A new lineage of Cryptococcus gattii (VGV) discovered in the Central Zambezian Miombo Woodlands. MBio. 2019;10(6):e02306-e2319. https://doi.org/10.1128/mBio.02306-19.

7. Tomazin R, Matos T, Meis JF, Hagen F. Molecular characterization and antifungal susceptibility testing of sequentially obtained clinical Cryptococcus deneoformans and Cryptococcus neoformans isolates from Ljubljana, Slovenia. Mycopathologia. 2018;183(2):371-80. https:// doi.org/10.1007/s11046-017-0214-9.

8. Wongsuk T, Homkaew A, Faksri K, Thongnak C. Multilocus sequence typing and whole genome sequence analysis of Cryptococcus neoformans isolated from clinical specimens in Vajira Hospital, Bangkok, Thailand. Mycopathologia. 2020;185(3):503-14. https://doi.org/10.1007/ s11046-020-00456-7.

9. Xess I, Pandey M, Dabas Y, Agarwal R, Das S, Srivastava PMV, Thakur R, Sharma S, Mani P, Biswas A, Bhowmik D, Das BK, Singh R, Panda P, Singh G, Phukan AC, Yhome M, Valsan C, Kindo AJ. Multilocus sequence typing of clinical isolates of Cryptococcus from India. Mycopathologia. 2021. https://doi.org/10.1007/s11046-020-00500-6.

10. Perfect JR, Dismukes WE, Dromer F, Goldman DL, Graybill JR, Hamill RJ, Harrison TS, Larsen RA, Lortholary O, Nguyen MH, Pappas PG, Powderly WG, Singh N, Sobel JD, Sorrell TC. Clinical practice guidelines for the management of cryptococcal disease: 2010 update by the Infectious Diseases Society of America. Clin Infect Dis. 2010;50(3):291-322. https://doi.org/10.1086/649858.

Publisher's Note Springer Nature remains neutral with regard to jurisdictional claims in published maps and institutional affiliations. 